\title{
Evaluation of the dispersion of carbon nanotubes in an elastomeric polyurethane and fatigue test
}

\author{
Felipe Luiz Queiroz Ferreira1', Magnovaldo Carvalho Lopes ${ }^{1}$, Ana Paula Mendes Lopes ${ }^{1}$, \\ Rodrigo Lassarote Lavall ${ }^{1}$ and Glaura Goulart Silva ${ }^{1 *}$
}

\section{${ }^{1}$ Centro de Tecnologia em Nanomateriais, Instituto de Ciências Exatas, Universidade Federal de Minas Gerais - UFMG, Belo Horizonte, MG, Brasil \\ *glaura@qui.ufmg.br}

\begin{abstract}
Two series of polyurethane (PU) and carbon nanotubes (CNT) based composites with $0.0,0.25,0.5$ and 1.0 mass \% of CNT were obtained from diluting a commercial masterbatch with 30 mass $\%$ CNT and using two different dispersion methods. The quality of the dispersions was assessed using optical microscopy, and scanning and transmission electron microscopies. These tests showed that high controlled shear stress is necessary to produce composites with nanoscale dispersion: the elastic modulus improved by an average of $38 \%$ in the case of the high-shear dispersed materials in comparison with the neat polymer. A specific fatigue test conducted by dynamic mechanical analysis was first used in this work to compare the neat PU with the CNT/PU nanocomposites. The number of cycles to failure increased from 2700 for the neat polymer to 3200 for the 0.5 mass $\%$ CNT based nanocomposite; the elongation at failure increased by $145 \%$ in the test conditions.
\end{abstract}

Keywords: carbon nanotubes, elastomeric polyurethane, mechanical properties, fatigue.

How to cite: Ferreira, F. L. Q., Lopes, M. C., Lopes, A. P. M., Lavall, R. L., \& Silva, G. G. (2019). Evaluation of the dispersion of carbon nanotubes in an elastomeric polyurethane and fatigue test. Polimeros: Ciência e Tecnologia, 29(1), e2019012. https://doi.org/10.1590/0104-1428.02718

\section{Introduction}

The extraordinary properties of carbon nanotubes $(\mathrm{CNT})^{[1-3]}$ have motivated large efforts to apply them as reinforcing agents in polymer composites ${ }^{[4,5]}$. The success, however, is being limited by the difficulties to disperse the nanomaterial and promote a good interaction with polymer chains at the interfaces. Various strategies using different processing equipment/methods, have been tested to improve dispersion: high shear mixers, three roll-mill, or planetary mixers in the case of resin to thermosets ${ }^{[6-10]}$; and extrusion and injection in the case of thermoplastics ${ }^{[11,12]}$. Companies commercialize masterbatches with high concentrations of CNT up to 50 mass $\%$. The high concentration of CNT increases significantly the viscosity of the masterbatches, leading liquid resins to be stored and commercialized as solid pellets. Masterbatches of CNT are available for thermoplastic (polyethylene, polypropylene, etc.) and for thermoset resins (epoxy and polyurethane)

Abbasi et al. ${ }^{[13]}$ produced composites of polypropylene (PP) and carbon nanotubes from a 20 mass $\%$ commercial masterbatch using a twin-screw extruder for dilution. They reported that processing at low temperature and high speed increased the shear mixing, which in turn broke off the agglomerates of CNT, resulting in a better dispersion of the nanotubes and increase in the electrical conductivity of the composites. Pötschke et al. ${ }^{[14]}$ used a Haake mixer coupled with a twin-screw extruder to produce composites of polycarbonate and carbon nanotubes from a commercial

masterbatch with 15 mass \%. The authors obtained SEM images showing the CNT covered by the polymer and randomly oriented. Cryofracture image of those composites after dilution shows that the cracks propagated through the matrix. The carbon nanotubes, however, appear to have bridged the cracks in the matrix, reinforcing the strength of the composite. Mansour et al. ${ }^{[15]}$ produced composites of thermoplastic polyurethane (TPU) and carbon nanotubes from a $10 \%$ mass masterbatch to evaluate mechanical properties such as hardness and compression strength. They showed that the use of carbon nanotubes increased hardness by up to $13 \%$ and modulus by up to $256 \%$. Additional reports featuring nanocomposites of thermoset polyurethane based on commercial masterbatchs have not been found. As such, to the best of our knowledge, this is the first work on this subject.

Polyol resins are used as precursors of polyurethane elastomers (PU). This highly viscous liquid at room temperature can receive CNT in polyol masterbatches, which reacts with isocyanates producing PU. PU elastomers are versatile materials that can be employed in industrial equipment such as bend stiffeners in the off shore oil industry and conveyor belts in the mining industry ${ }^{[16,17]}$. For these industrial applications, there are complex requirements of mechanical properties, especially tear strength, abrasion resistance, and fatigue behavior. Therefore, they can benefit from new formulations that could show real gain in different 
properties simultaneously. The introduction of small amounts of CNT has the potential to increase performance for this kind of highly demanded materials. This was already shown by our previous work ${ }^{[9,10,18]}$, as well as that of other authors ${ }^{[19-21]}$.

The PU elastomer chains are composed by the polyol segments and the isocyanate segments, which contribute to the flexibility, mechanical resistance, and fatigue resistance of these materials ${ }^{[22-24]}$. Conventional fatigue tests are conducted in servo-hydraulic testing machines able to apply cyclic forces to specimen and measure the number of cycles to failure. This type of testing is frequently time-consuming and expensive. A new fatigue test for the PU elastomers and its nanocomposites using a dynamic mechanical analyzer (DMA) was tested in this work. Similar fatigue tests were employed for metals ${ }^{[25]}$ or other polymers such as PTFE and $\mathrm{SBR}^{[26,27]}$, but it is the first time that the fatigue of a PU elastomer nanocomposite was evaluated by DMA.

Two types of dispersion methodologies were thus investigated: the dispersion proposed by the supplier of a commercial masterbatch of CNT and the dispersion optimized by our group, employing three-roll mills ${ }^{[9,10]}$. The quality and mechanical properties of these resulting dispersions were compared and a fatigue test by DMA was used to investigate the influence of CNT, under cyclic effort, in the lifetime of the material.

\section{Materials and Methods}

\subsection{Materials}

A masterbatch of multiwalled carbon nanotubes was purchased from Arkema (France) ${ }^{[28]}$. Supplier reports that the masterbatch contains 30 mass $\%$ of CNT in polyether polyol resin (Graphistrength ${ }^{\circledR}$ C PU1-30). Plastiprene (Brazil) kindly provided polytetramethylene ether glycol (PTMEG), toluene diisocyanate (TDI), 1,4-butanediol, and 4,4-methylene-bis-ortho-chloroaniline (MOCA) for use in the synthesis of the elastomeric polyurethane.

\subsection{Preparation of MWCNT/PU composites}

Two series of composites were prepared by adding different amounts of the masterbatch in PTMEG and reacting with TDI and 1,4 butanediol. The prepolymer synthesized was cross-linked with $\mathrm{MOCA}^{[9,10]}$. The final concentrations of the composites were $0.25,0.50$ and 1 mass $\%$ of carbon nanotubes. Two types of dispersion methodologies were tested to disperse the masterbatch in the PTMEG. In the first instance, as proposed by the supplier, composites were prepared by adding the masterbatch under mechanical stirring (IKA, RW20, 350 RPM, $100{ }^{\circ} \mathrm{C}$, overnight). In the second one, composites were prepared by adding masterbatch using a high shear mechanical mixer (IKA, T25, 20,000 RPM, 5 min) and subsequently with a three roll mill (Exakt, 80E, 5 runs, gap 5:10, 300 RPM). Two reference samples (without carbon nanotubes) were also processed using the two methods.
The procedures of masterbatch dispersion are summarized in Table 1.

\subsection{Characterization}

The characterization of the samples included a study of the morphology of the masterbatch using scanning electron microscopy (SEM) in a Quanta 200-FEG / FEI microscope; the cryo-fracturing of a masterbatch pellet with liquid nitrogen to analyze the surface; and the examination of carbon nanotubes extracted from the masterbatch with acetone by transmission electron microscopy (TEM) on a Tecnai G2-20 / FEI microscope. Additionally, thermogravimetric analyses of the masterbatch were performed in a synthetic air atmosphere with a heating rate of $10^{\circ} \mathrm{C} \mathrm{min}^{-1}$ from room temperature to $1000{ }^{\circ} \mathrm{C}$, using the Q5000 TA instruments apparatus. Samples of the masterbatch dilutions in PTMEG ( 0.10 mass $\%)$, prior to cure, were characterized by optical microscopy (OM) in transmission mode using an Olympus BX50F microscope with a magnification of 100x. The same $\mathrm{OM}$ analysis was also done for composite fragments in order to evaluate the dispersion of the nanotubes in the final material. Furthermore, the mechanical properties of the composites were tested in an Emic DL10.000 universal testing machine; elastic modulus was asserted using ASTM D638 and replicates of five dog bone specimens, type IV, with $115 \mathrm{~mm}$ (length), $6 \mathrm{~mm}$ (width) and $3 \mathrm{~mm}$ (thickness). The secant modulus at $6 \%$ elongation was used for evaluation. The tests were performed at $23 \pm 2{ }^{\circ} \mathrm{C}$ and at relative humidity of $50 \pm 10 \%$ using an extensometer, a load cell of $50 \mathrm{kgf}$, and a displacement velocity of $50.0 \mathrm{~cm} \cdot \mathrm{min}^{-1}$.

Finally, a fatigue test conducted using the tensile mode DMA was developed for this work. The test was performed under isotherm at $50{ }^{\circ} \mathrm{C}$, the specimens were oscillated with a frequency of $5 \mathrm{~Hz}$ and a force of $6 \mathrm{~N}$ until rupture. The specimen's dimensions were $20 \mathrm{~mm}$ (length) $\times 6 \mathrm{~mm}$ (width) $\times 0.5 \mathrm{~mm}$ (thickness) and they were notched to induce crack propagation. Five specimens of each sample were tested and the two extreme results were excluded, thus, the data presented is in triplicates. Several experiments, using different temperatures, were conducted with specimens of different dimensions, with different frequencies and forces, and without/with notch to find the test parameters that revealed the fatigue behavior of the neat elastomeric PU and nanocomposites studied in this work. The extensive preliminary work (not reported here) showed that within the low limit of force that the DMA allows $(6 \mathrm{~N})$, it is necessary to introduce the notch and prepare thin specimens in order to get a clear fatigue response in this kind of PU.

\section{Results and Discussions}

Figure 1a-c shows: (a) TGA analyses with a mass loss of $29 \%$ at approximately $550{ }^{\circ} \mathrm{C}$, which is associated to the decomposition of carbon nanotubes confirming the nanotube

Table 1. Procedures of masterbatch dispersion.

\begin{tabular}{ll}
\hline & \multicolumn{1}{c}{ Dispersion methods } \\
\hline Method 1 & Dispersion with mechanical stirring, 350 RPM, $100{ }^{\circ} \mathrm{C}$, overnight. \\
Method 2 & Dispersion with high shear, 20.000 RPM for 5 min and three-roll mill, 5 runs, gap 5:10, 300 RPM. \\
\hline
\end{tabular}


content reported by the supplier ${ }^{[28]}$; (b) the appearance of the masterbatches in the form of pellets with a high concentration of carbon nanotubes; and (c) the cryo-fractured image of a pellet, in which CNT can be visualized pulling off the matrix, respectively. Figure 1d shows a TEM image of the carbon nanotubes extracted from the masterbatch with acetone, displaying nanotubes with an average of $10 \mathrm{~nm}$ of external diameter. The characterization of the masterbatch and the MWCNT in the material indicated that this commercially available system has desirable features for the employment as additive in elastomeric PU developed for industrial demands ${ }^{[9,10,13]}$

Figure 2 shows optical microscopy images of diluted samples of the masterbatchs in PTMEG with 0.10 mass \% of CNT, prior to cure, produced through the two procedures presented in this work (Table 1). The method of dispersion 1 using only mechanical stirring was recommended by the supplier, however, it was not enough to disperse the carbon nanotubes that remained agglomerated in small grains, as indicated in Figure 2a by the arrows highlighting the aggregates. Method 2, showcased the need of high and controlled shear stress to produce composites with nanoscale dispersion, Figure $2 \mathrm{~b}$. The morphology of Figure $2 \mathrm{~b}$ typically results from the shearing of the CNT aggregates by the roll mill; it allows the formation of nanotube networks in all directions, consequently permitting improvements in the mechanical and electrical properties of the nanocomposite ${ }^{[29]}$.

Figure 3 a shows optical images of composite fragments with 0.25 and 0.50 mass $\%$ of CNT and (b) SEM images of composite fragments with 0.50 mass $\%$ of CNT, which show how efficient dispersion, obtained by processing method 2 , was maintained even after curing. The larger black spots of CNT aggregates, which are present after method 1 dispersion, are observable at the top of Figure $3 \mathrm{a}$, some of which have been indicated by arrows. Much smaller aggregates are observed in composites produced by method 2 as indicated by the arrows in the lower half of Figure 3a. SEM images furthermore confirm these observations: for the method 1 dispersion, the high magnified image (top-right of Figure 3b) shows the inside of an agglomerate of approximately $10 \mu \mathrm{m}$ diameter. The SEM images in two magnifications on the bottom of Figure $3 \mathrm{~b}$ show the typical dispersion achieved with the high shear method 2 with carbon nanotubes better distributed and pulled out of the PU matrix.

The composites processed by the most efficient dispersion method (method 2), as demonstrated by the morphological study, were tested for tensile strength and Figure $4 \mathrm{~b}$ shows
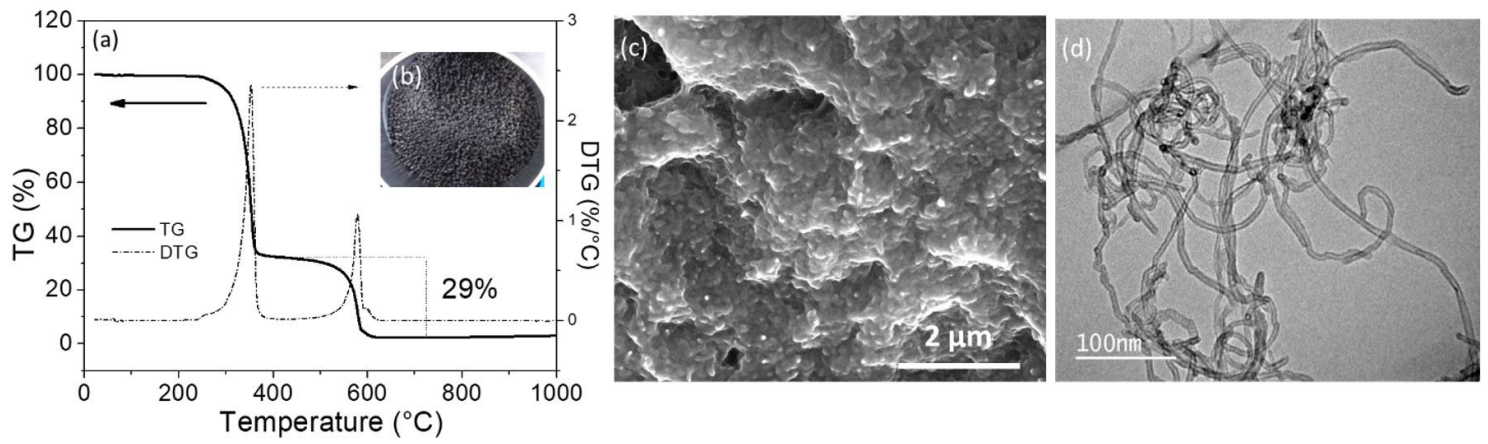

Figure 1. Commercial masterbatch: (a) TGA curve; (b) inset - masterbatch sample; (c) SEM image of the cryofracturated pellet; (d) TEM image of the carbon nanotube extracted from the masterbatch.
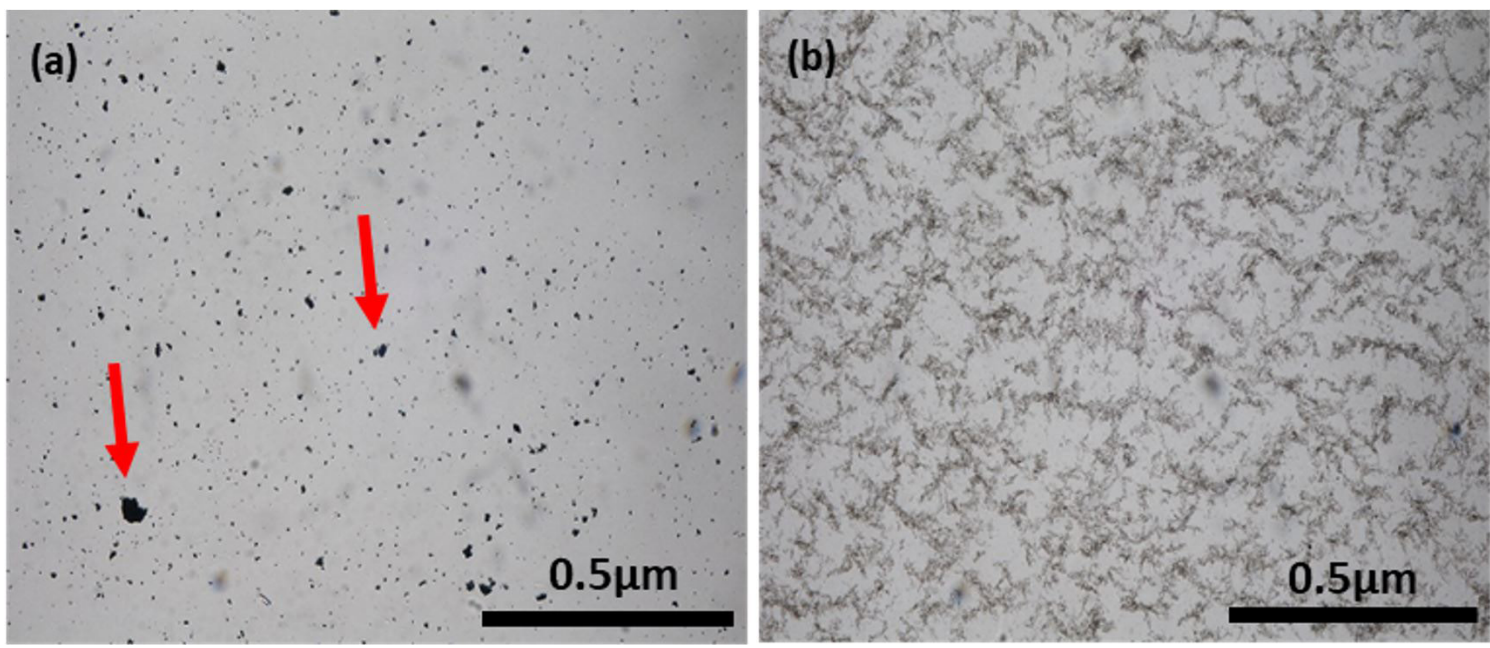

Figure 2. Optical microscopy images for the dispersion (prior to cure) of masterbatch on PTMEG to a 0.10 mass $\%$ composite: (a) Method 1: dispersion by mechanical stirring; and (b) Method 2: dispersion with high shear and three-roll mill. 
(a)

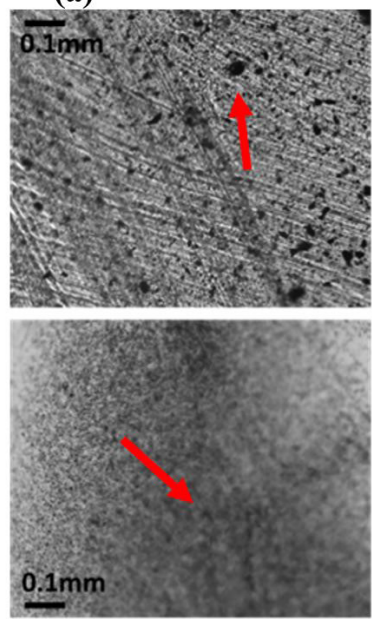

$0.25 \%$
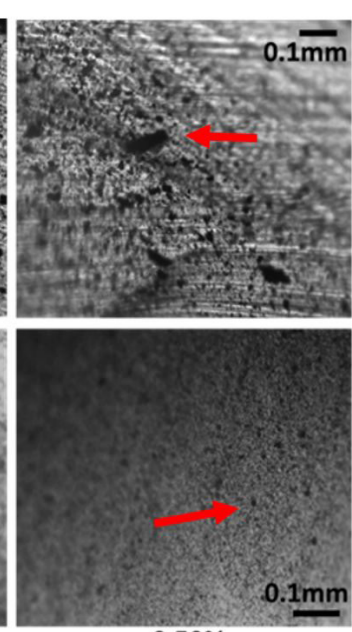

(b)
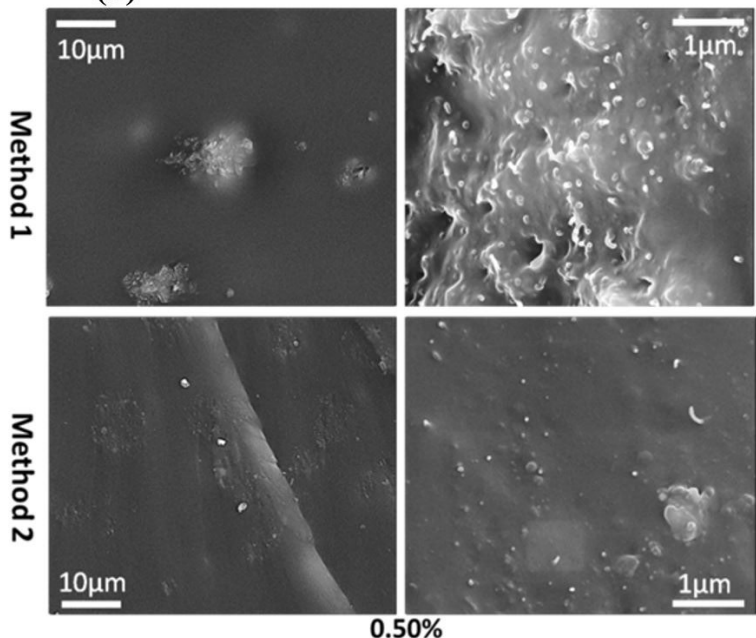

Figure 3. (a) Optical and (b) SEM images of CNT/PU composite fragments prepared with commercial masterbatch dilution by two different methods. Method 1 (top) is mechanical stirring and Method 2 (bottom) is high shear/roll mill processing. The concentrations of CNT in PU are indicated in the bottom of the figure.
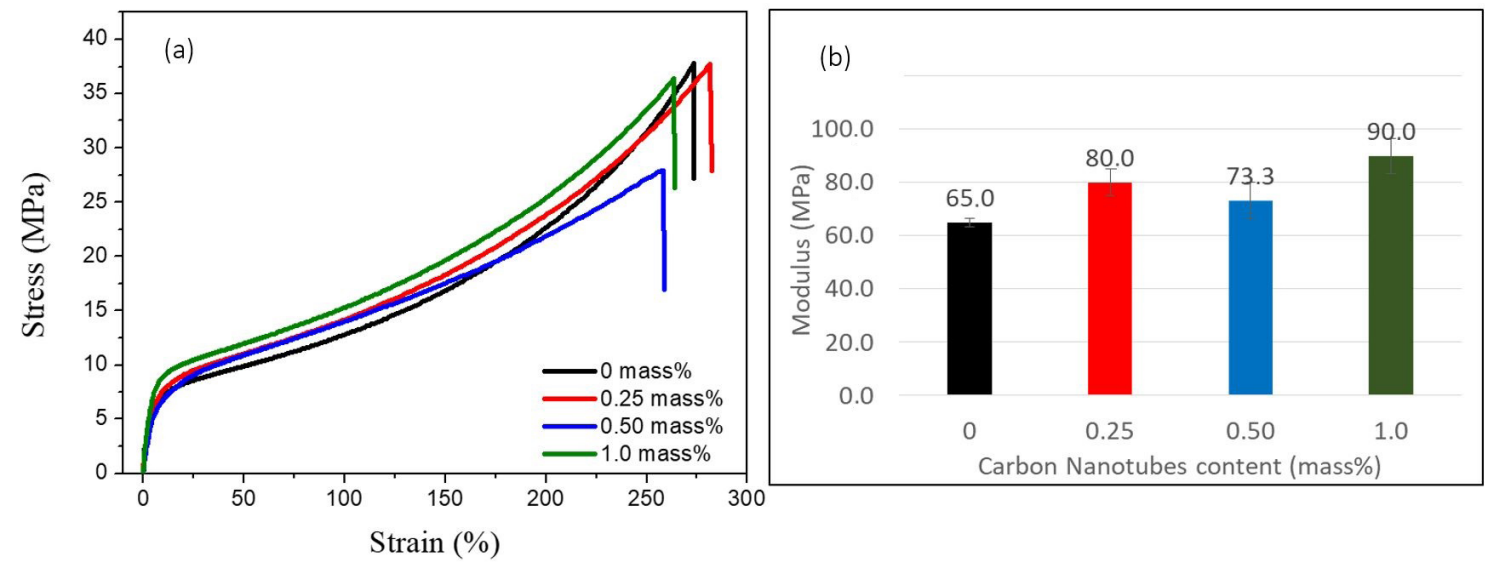

Figure 4. Results of mechanical testes for PU and nanocomposites prepared by Method 2: (a) Engineering stress-strain representative curves (from a minimum of five replicates); (b) Secant modulus at $6 \%$ elongation for elastomeric neat PU and composites.

the secant elastic modulus at $6 \%$ elongation. The elastic modulus increased up to $38 \%$ in comparison with the reference sample. Increases in modulus were also observed by Lopes et al. ${ }^{[10]}$, a study in which up to $47 \%$ increase in the stiffness of the composites was obtained with addition of $0.5 \%$ MWCNT in PU. Mansour et al. ${ }^{[15]}$ obtained similar increases in composite stiffness with 1 mass $\%$ of nanotubes in a thermoplastic polyurethane formulation.

DMA analysis presented in Figure 5 shows that the storage modulus of the composite is similar to the neat PU at room temperature. Nevertheless, for temperatures above $50^{\circ} \mathrm{C}$, it is noted that storage moduli of 1 mass $\%$ composites are superior to the reference by up to $20 \%$ at $120{ }^{\circ} \mathrm{C}$, for example. Tan $\delta$ curves show a large event associated to glass transition from $-50^{\circ} \mathrm{C}$ to $100^{\circ} \mathrm{C}$. The main peak of $\tan \delta$ is found at $50{ }^{\circ} \mathrm{C}$ and a shoulder peak can be seen at $-30^{\circ} \mathrm{C}$. Neat PU and 1 mass\% CNT based composite both show no variation in the peak temperatures at the $\tan \delta$ curve. The DMA curves obtained in this study are very similar to the ones showed in the work of Lopes et al..$^{[10]}$. In that case, the same morphology of elastomeric PU employed in the present work was produced with the addition of MWCNT by high shear mixing. The difference is that herein the CNT was added with the help of a commercial masterbatch. Therefore, if high shear dispersion methodology is applied, the results obtained with elastomeric PU/MWCNT are reproducible.

In an effort to assess this important characteristic of an elastomeric material such as PU, fatigue behavior tests by DMA were also performed in this study. The industrial applications of elastomeric PU in oil, gas and mining industries are very demanding on the material because they are used in harsh conditions of impact, high temperature and need long life cycles of sometimes over a decade. Figure $6 a, b$ presents images of the test pieces used in these experiments as well as 

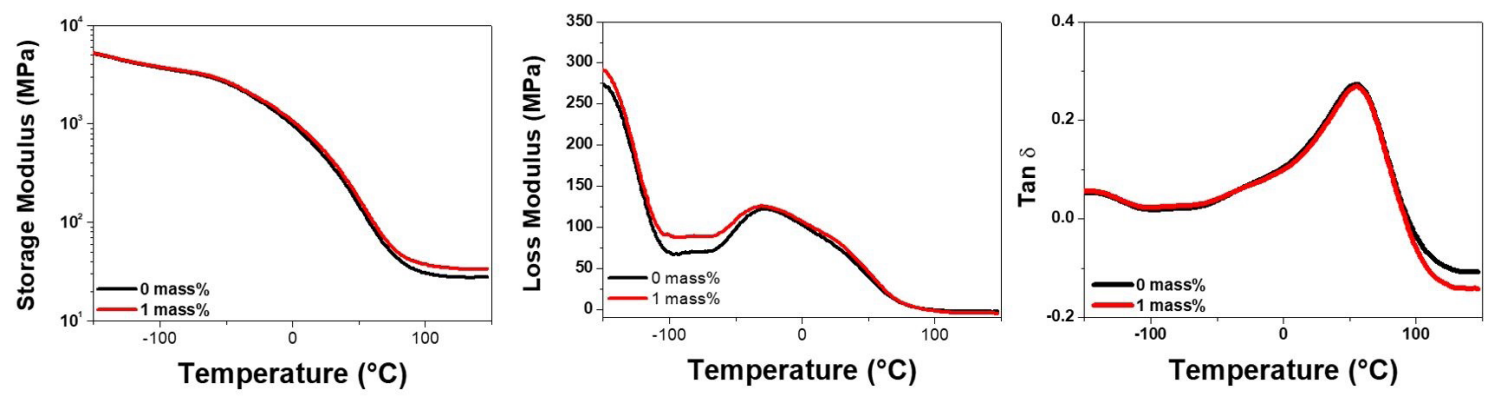

Figure 5. DMA results. Storage modulus, Loss modulus and Tan $\delta$ of neat elastomeric polyurethane and nanocomposite with 1.0 mass $\%$ of CNT prepared with a commercial masterbatch dilution by Method 2.
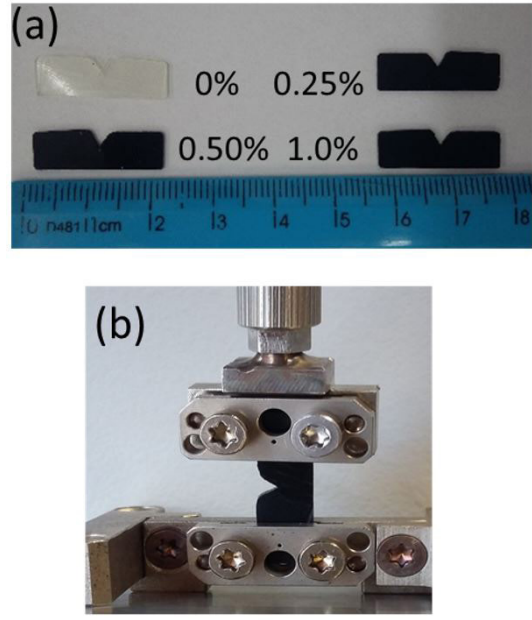

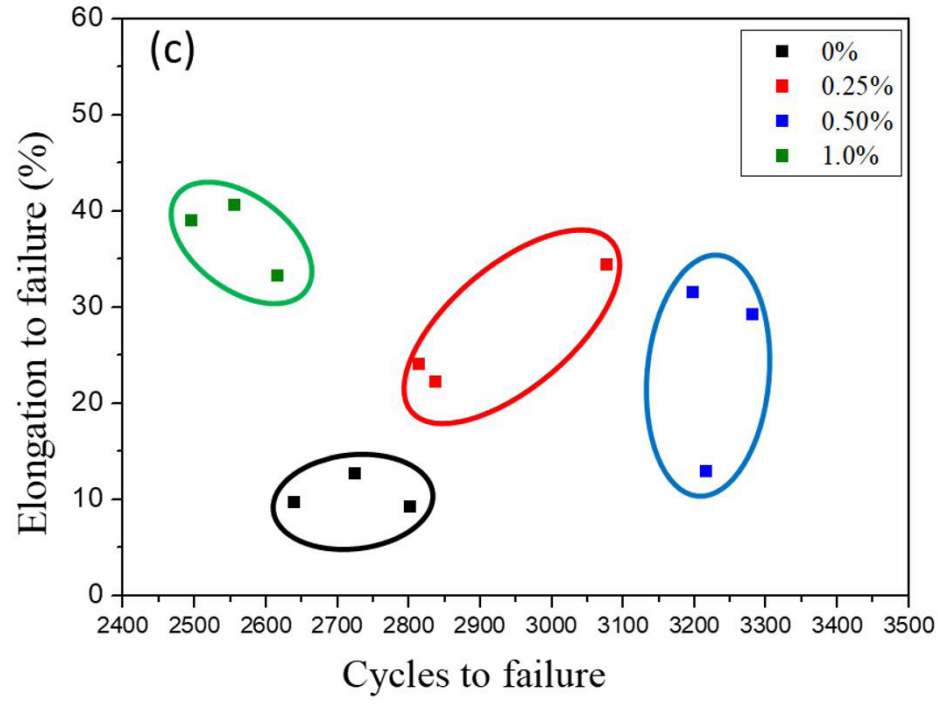

Figure 6. (a) Fatigue samples; (b) tensile probe apparatus; and (c) fatigue behavior for neat PU and nanocomposites.

the tensile device used in the tests. In Figure 6c, the fatigue behavior of the samples was examined based on the results of the $\%$ of elongation at failure as a function of number of cycles to failure. The results showed a dispersion of data allowing only a qualitative comparison between the neat $\mathrm{PU}$ and the nanocomposites. We have decided to present the three more consistent results which are marked in the image with an ellipsis rather than averaging. Only after 2400 cycles do the notched-thin specimens start to fail in conditions of $50^{\circ} \mathrm{C}$, tensile of $6 \mathrm{~N}$ and $5 \mathrm{~Hz}$. The neat PU showed approximately 2700 cycles up to failure with about $10 \%$ elongation. It is clear that the composites presented higher $\%$ of deformation before failure, with significant increases of up to $245 \%$ in elongation for 1.0 mass $\%$ composite in comparison with the neat polymer. Composites with 0.25 and 0.50 mass\% of nanotubes show an increase in the number of cycles to failure of 7 and $19 \%$, respectively. The average of the results showed in Figure 6 are summarized in Table 2.

The fatigue test employed in this work showed a clear tendency for expanded lifespan and increased ductility for the samples with additions of carbon nanotubes. Although the conditions of this test by DMA make it difficult to compare with other references, the observation of the results allows
Table 2. Average of fatigue test results.

\begin{tabular}{ccc}
\hline Sample & Cycles to failure & $\begin{array}{c}\text { Elongation to } \\
\text { failure / } \%\end{array}$ \\
\hline $0 \%$ & $2722 \pm 81$ & $11 \pm 2$ \\
$0.25 \%$ & $2910 \pm 146$ & $27 \pm 7$ \\
$0.50 \%$ & $3232 \pm 44$ & $25 \pm 10$ \\
$1.00 \%$ & $2556 \pm 60$ & $38 \pm 4$ \\
\hline
\end{tabular}

for confirmation of effective gains in the fatigue resistance of the nanocomposites. Loos et al. ${ }^{[19]}$ have been studied the effects of carbon nanotube (CNT) inclusion on cyclic fatigue behavior using a convectional tension fatigue test and the tensile properties of polyurethane (PU) composites. They have shown a similar tendency as what was observed in the present work, i.e. the incorporation of CNT extended the life of PU before fatigue in the high-stress amplitude and low-cycle regime by up to $248 \%$. Loos et al. ${ }^{[19]}$ state that the micrographs indicate the key mechanisms for enhancement in fatigue life as CNT crack-bridging and pull-out. Moreover, the effective enhancement in the properties of PU obtained in this study is attributed to successful dispersion of the CNTs and improved interaction between filler and matrix, suggesting an energy absorbing mechanism responsible for the increase in the fatigue life. 


\section{Conclusions}

In this study carbon nanotubes were used as efficient mechanical reinforcement for elastomeric polyurethane. This is seen by the increase in elastic modulus and storage modulus. It was also observed in the significant contribution of the carbon nanotubes for the increased fatigue strength, i.e. elongation and number of cycles at failure. This reinforcement was possible because of an efficient dispersion method for a commercial masterbatch achieved using techniques that generated high shear and produced composites with nanoscale dispersion. The nanocomposites PU/CNT have mechanical characteristics that make them possible substitutes in applications that demand high performance materials.

\section{Acknowledgements}

The authors thank the Petrobras Company for support. They also thank Daniel Freller from Plastiprene, a Brazilian producer of polyurethane parts. Pró-Reitoria de Pesquisa of UFMG, CNPq, Fapemig and the Microscopic Center (UFMG) are also acknowledged for their support.

\section{References}

1. Wong, E. W., Sheehan, P. E., \& Lieber, C. M. (1997). Nanobeam mechanics: elasticity, strength, and toughness of nanorods and nanotubes. Science, 277(5334), 1971-1975. http://dx.doi. org/10.1126/science.277.5334.1971.

2. Yu, M. F., Lourie, O., Dyer, M. J., Moloni, K., Kelly, T. F., \& Ruoff, R. S. (2000). Strength and breaking mechanism of multiwalled carbon nanotubes under tensile load. Science, 287(5453), 637-640. http://dx.doi.org/10.1126/science.287.5453.637. PMid:10649994.

3. Treacy, M. M. J., Ebbesen, T. W., \& Gibson, T. M. (1996). Exceptionally high young's modulus observed for individual carbon nanotubes. Nature, 381(6584), 680-687. http://dx.doi. org/10.1038/381678a0.

4. Silva, W. M., Ribeiro, H., Neves, J. C., Sousa, A. R., \& Silva, G. G. (2015). Improved impact strength of epoxy by the addition of functionalized multiwalled carbon nanotubes and reactive diluent. Journal of Applied Polymer Science, 132(19), 42587-42598. http://dx.doi.org/10.1002/APP.42587.

5. Ribeiro, B., Botelho, E. C., \& Costa, M. L. (2015). Estudo das propriedades elétricas e térmicas de compósitos nanoestruturados de poli(sulfeto de fenileno) reforçados com nanotubos de carbono. Polímeros Ciência e Tecnologia, 25(1), 94-100. http:// dx.doi.org/10.1590/0104-1428.1728.

6. Olowojoba, G., Sathyanarayana, S., Caglar, B., Kiss-Pataki, B., Mikonsaari, I., Hübner, C., \& Elsner, P. (2013). Influence of process parameters on the morphology, rheological and dielectric properties of three-roll-milled multiwalled carbon nanotube/epoxy suspensions. Polymer, 54(1), 188-198. http:// dx.doi.org/10.1016/j.polymer.2012.11.054.

7. Yedra, Á., Gutiérrez-Somavilla, G., Manteca-Martínez, C., González-Barriuso, M., \& Soriano, L. (2016). Conductive paints development through nanotechnology. Progress in Organic Coatings, 95, 85-90. http://dx.doi.org/10.1016/j. porgcoat.2016.03.001.

8. Rosca, I. D., \& Hoa, S. V. (2009). Highly conductive multiwall carbon nanotube and epoxy composites produced by three-roll milling. Carbon, 47(8), 1958-1968. http://dx.doi.org/10.1016/j. carbon.2009.03.039.

9. Lopes, M. C., Trigueiro, J. P. C., Castro, V. G., Lavall, R. L., \& Silva, G. G. (2016). Otimização do processo de dispersão de nanotubos de carbono em poliuretano termorrígido. Polímeros: Ciência e Tecnologia, 26(1), 81-91. http://dx.doi. org/10.1590/0104-1428.2087.

10. Lopes, M. C., Castro, V. G., Seara, L. M., Diniz, V. P. A., Lavall, R. L., \& Silva, G. G. (2014). Thermosetting polyurethanemultiwalled carbon nanotube composites: thermomechanical properties and nanoindentation. Journal of Applied Polymer Science, 131(23), 41207-41214. http://dx.doi.org/10.1002/ app.41207.

11. Kasaliwal, G. R., Pegel, S., Göldel, A., Pötschke, P., \& Heinrich, G. (2010). Analysis of agglomerate dispersion mechanisms of multiwalled carbon nanotubes during melt mixing in polycarbonate. Polymer, 51(12), 2708-2720. http://dx.doi. org/10.1016/j.polymer.2010.02.048.

12. Müller, T. M., Krause, B., Kretzschmar, B., \& Pötschke, P. (2011). Influence of feeding conditions in twin-screw extrusion of PP/ MWCNT composites on electrical and mechanical properties. Composites Science and Technology, 71(13), 1535-1542. http:// dx.doi.org/10.1016/j.compscitech.2011.06.003.

13. Abbasi, S., Derdouri, A., \& Carreau, P. J. (2014). Carbon nanotube conductive networks through the double percolation concept in polymer systems. International Polymer Processin, 29(1), 13-27. http://dx.doi.org/10.3139/217.2778.

14. Pötschke, P., Fornes, T. D., \& Paul, D. R. (2002). Rheological behavior of multiwalled carbon nanotube/polycarbonate composites. Polymer, 43(11), 3247-3255. http://dx.doi. org/10.1016/S0032-3861(02)00151-9.

15. Mansour, G., Tsongas, K., Tzetzis, D., \& Tzikas, K. (2017). Dynamic mechanical characterization of polyurethane/multiwalled carbon nanotube composite thermoplastic elastomers. Polymer-Plastics Technology and Engineering, 56(14), 15051515. http://dx.doi.org/10.1080/03602559.2016.1277243.

16. Engels, H. W., Pirkl, H. G., Albers, R., Albach, R. W., Krause, J., Hoffmann, A., Casselmann, H., \& Dormish, J. (2013). Polyurethanes: versatile materials and sustainable problem solvers for todays challenges. Angewandte Chemie International Edition, 52(36), 9422-9441. http://dx.doi.org/10.1002/ anie.201302766. PMid:23893938.

17. Aquino, F. G., Sheldrake, T., Clevelario, J., Pires, F., \& Coutinho, F. M. B. (2010). Estudo do envelhecimento de poliuretanos aplicados na indústria de petróleo. Polímeros: Ciência e Tecnologia, 20(1), 33-38. http://dx.doi.org/10.1590/ S0104-14282010005000006.

18. Lima, A. M. F., Castro, V. G., Borges, R. S., \& Silva, G. G. (2012). Electrical conductivity and thermal properties of functionalized carbon nanotubes/polyurethane composites. Polimeros Ciência e Tecnologia, 22(2), 117-124. http://dx.doi. org/10.1590/S0104-14282012005000017.

19. Loos, M. R., Yang, J., Feke, D. L., Manas-Zloczower, I., Unal, S., \& Younes, U. (2013). Enhancement of fatigue life of polyurethane composites containing carbon nanotubes. Composites. Part B, Engineering, 44(1), 740-744. http://dx.doi. org/10.1016/j.compositesb.2012.01.038.

20. Shokry, S. A., El Morsi, A. K., Sabaa, M. S., Mohamed, R. R., \& El Sorogy, H. E. (2015). Synthesis and characterization of polyurethane based on hydroxyl terminated polybutadiene and reinforced by carbon nanotubes. Egyptian Journal of Petroleum, 24(2), 145-154. http://dx.doi.org/10.1016/j.ejpe.2015.05.008.

21. McClory, C., McNally, T., Brennan, G. P., \& Erskine, J. (2007). Thermosetting polyurethane multiwalled carbon nanotube composites. Journal of Applied Polymer Science, 105(3), 1003-1011. http://dx.doi.org/10.1002/app.26144.

22. Rueda-Larraz, L., d'Arlas, B. F., Tercjak, A., Ribes, A., Mondragon, I., \& Eceiza, A. (2009). Synthesis and microstructure-mechanical property relationships of segmented polyurethanes based on a PCL-PTHF-PCL block copolymer as soft segment. European 
Polymer Journal, 45(7), 2096-2109. http://dx.doi.org/10.1016/j. eurpolymj.2009.03.013.

23. Jimenez, G., Asai, S., Shishido, A., \& Sumita, M. (2000). Effect of the soft segment on the fatigue behavior of segmented polyurethanes. European Polymer Journal, 36(9), 2039-2050. http://dx.doi.org/10.1016/S0014-3057(99)00241-4.

24. Pichon, P. G., David, L., Méchin, F., \& Sautereau, H. (2010). Morphologies of cross-linked segmented polyurethanes. evolution during maturation and consequences on elastic properties and thermal compressive fatigue. Macromolecules, 43(4), 1888-1900. http://dx.doi.org/10.1021/ma901602y.

25. Nikulin, S. A., Markelov, V. A., Gusev, A. Y., Nechaykina, T. A., Rozhnov, A. B., Rogachev, S. O., \& Zadorozhnyy, M. Y. (2013). Low-cycle fatigue tests of zirconium alloys using a dynamic mechanical analyzer. International Journal of Fatigue, 48, 187-191. http://dx.doi.org/10.1016/j.ijfatigue.2012.10.019.

26. Aindow, T. T., \& O’Neill, J. (2011). Use of mechanical tests to predict durability of polymer fuel cell membranes under humidity cycling. Journal of Power Sources, 196(8), 38513854. http://dx.doi.org/10.1016/j.jpowsour.2010.12.031.

27. Rublon, P., \& Favier, A. (2015). Effect of antioxidants on the fatigue crack growth behavior of filled SBR compounds. Procedia Engineering, 133, 161-170. http://dx.doi.org/10.1016/j. proeng.2015.12.644.

28. Arkema. (2010). Arkema offers new Graphistrength masterbatches. Additives for Polymers, 2010(4), 5. http://dx.doi.org/10.1016/ S0306-3747(10)70061-0.

29. Hollertz, R., Chatterjee, S., Gutmann, H., Geiger, T., Nuesch, F. A., \& Chu, B. T. T. (2011). Improvement of toughness and electrical properties of epoxy composites with carbon nanotubes prepared by industrially relevant processes. Nanotechnology, 22(12), 125702. http://dx.doi.org/10.1088/0957-4484/22/12/125702. PMid:21317490.

Received: Mar. 29, 2018

Revised: Oct. 18, 2018

Accepted: Oct. 29, 2018 